\title{
Выбор структуры капитала компаниями стран БРИК и Восточной Европы: эмпирический анализ
}

\author{
Кокорева M.C. ${ }^{13}$
}

В данной статье представленьл результаты эмпирического тестирования динамической компромиссной концепщии структуры капитала на данных компаний стран БРИК и Восточной Европы. На выборке 403 крупных публичных компаний за 2002-2010 финансовые годы выявлена применимость компромиссной динамической конщепции $в$ качестве мотива выбора соотношения собственного и заемного капиталов компаний. При этом мотивы отслеживания рынка капитала, а также детерминанты концепиии порядка финансирования также оказывают воздействие на выбор структуры капитала посредством влияния на скорость приспособления, в то время как агентские $u$ поведенческие факторы значимы при определении целевого уровня долговой нагрузки.

\section{JEL: $G 32$}

Ключевые слова: структура капитала, динамическая компромиссная кониепция, развивающиеся рынки капитала, теория порядка финансирования, теория отслеживания рынка

\section{Введение}

Выбор соотношения собственных и заемных источников финансирования, необходимых для долгосрочного развития компании, влияет на уровень ее инвестиционных рисков, потенциальные конфликты интересов между собственниками компании и кредиторами, собственниками и менеджментом, финансовыми и нефинансовыми стейкхолдерами. Изучению проблемы выбора данного соотношения посвящена обширная теоретическая и эмпирическая литература, однако компаниям, оперирующим в странах с развивающимся, недостаточно зрелым рынком капитала, уделено существенно меньшее внимание. Доступные в настоящий момент исследования относятся к ограниченному кругу восточноевропейских и азиатских стран и редко отражают результаты сравнительного анализа. Таким образом, вклад результатов данного исследования в финансовую литературу заключается в проведении сравнительного анализа выбора структуры капитала на данных 16 стран БРИК и Восточной Европы (BЕ). Финансовый кризис, начавшийся в 2007-2008 годах, не мог не сказаться на принятии решений менеджментом о структуре капитала, повлияв как на внешние институциональные и макроэкономические показатели, так и на внутренние показатели фирмы, приводящие к изменениям в соотношении собственного и заемного капиталов компании. Анализ изменений в мотивации менеджмента при выборе стратегического уровня заемного капитала в период кризиса позволит углубить текущее представление о формировании структуры капитала компаниями, функционирующими на развивающихся финансовых рынках.

\section{Обзор исследований структуры капитала на развивающихся финансовых рынках}

Существующее многообразие эмпирических исследований структуры капитала представлено работами, посвященными анализу детерминант и эмпирическому

\footnotetext{
${ }^{13}$ Преподаватель кафедры экономики и финансов фирмы Национального исследовательского университета «Высшая школа экономики», младший научный сотрудник научно-учебной лаборатории корпоративных финансов
} 
тестированию теорий формирования структуры капитала (теории порядка финансирования, компромиссной теории, теории отслеживания рынка, агентских, сигнальных и поведенческих мотивов).

В исследовании долгосрочных тенденций структуры капитала на данных 34 развивающихся рынков Миттон (Mitton, 2008) показал, что существенное увеличение долговой нагрузки в исследуемый им период 1980-2004 годов на развивающихся рынках капитала в большей степени может быть объяснено соответствующими изменениями фундаментальных детерминант компаний (размер капитала компании, доходность совокупного капитала, возможности роста, структура активов компании). Значимость традиционных детерминант выявил Панди (Pandey, 2001), анализируя выборку компаний Малайзии, а также Ниворожкин (Nivorozhkin, 2002) на данных компаний Венгрии. Однако традиционными детерминантами список факторов, влияющих на структуру капитала в развивающихся странах, не ограничивается. Бут и соавторы (Booth et al., 2001), Миттон (Mitton, 2008), Де Джонг (De Jong et al., 2008) выявили значимость макроэкономических факторов, оказывающих влияние на соотношение собственного и заемного капиталов.

Тестирование существующих концепций формирования структуры капитала на развивающихся рынках капитала представлено меньшим количеством работ.

Исследования, ставящие своей целью эмпирическое тестирование теории порядка финансирования на развивающихся рынках, приходят к противоречивым результатам. Ивашковская и Макаров (Ивашковская, Макаров, 2010) на данных европейских стран показывают, что теория порядка финансирования способна объяснить значимую долю новых заимствований на рынках Центральной и Восточной Европы (ЦВЕ), при этом часть выявленных авторами детерминант говорит в пользу значимости статической компромиссной теории. При анализе компаний из 23 стран Сейферт и соавторы не нашли подтверждения следованию теории порядка финансирования (Seifert, 2010). Однако Сеппа при анализе компаний Эстонии определил свойственное им следование теории порядка финансирования (Seppa, 2008). На выборке 50 крупнейших компаний Китая за период 20012003 Тонг и Грин (Tong, Green, 2005) показали, что поведение китайских компаний в отношении выбора структуры капитала в большей степени соотносится с теорией порядка финансирования.

Набор исследований поведенческих концепций в основном сосредоточен на тестировании теории отслеживания рынка, являющейся наиболее разработанной из класса поведенческих теорий. Исследование периода между первичным и последующими размещениями акций китайских компаний позволило Ни и соавторам установить незначимость классических концепций структуры капитала на данном рынке, однако выявленная устойчивая обратная зависимость долговой нагрузки от показателя оценки акций рынком позволила говорить о значимости теории отслеживания рынка (Ni et al., 2010). Более масштабное исследование было проведено Бесслером и соавторами, осуществившими эмпирическое тестирование гипотезы отслеживания рынка на данных компаний из 42 стран, позволившее авторам заключить, что выбор структуры капитала может быть, в том числе, объяснен с точки зрения отслеживания рынка (Bessler et al., 2011). На данных турецких компаний Умутлу установил, что менеджмент турецких фирм следует концепции отслеживания рынка капитала только в периоды так называемого «горячего» рынка первичных размещений (ситуации, когда количество размещений за период превышает медианное значение), в остальные периоды менеджмент в большей степени придерживается концепции порядка финансирования (Umutlu, 2008). Аналогичное исследование на данных бразильских компаний не выявило устойчивой зависимости уровня долговой нагрузки от колебаний курса акций компаний (Mendes et al., 2005).

Наконец, наиболее свежие работы посвящены тестированию динамической компромиссной концепции. Исследование Кларка и соавторов, проведенное на данных компаний 21 развитой и 19 развивающихся стран, позволило установить, что формирование структуры капитала на всех рынках может быть описано динамической компромиссной 
концепцией (Clark et al., 2009). Анализ влияния на скорость приспособления детерминант, отвечающих за экономическое, законодательное и политическое развитие стран, продолжили Озтекин и Фланнери, проведя анализ скорости приспособления компаний из 37 стран. Авторы подтвердили значимость как обозначенных выше параметров, так и таких факторов, как развитие корпоративного управления, налоговые режимы, доступ к внешнему финансированию (Öztekin, Flannery, 2012). Ниворожкин (Nivorozhkin, 2002; Nivorozhkin, 2005) в серии исследований на данных пяти европейских стран получил результаты, согласно которым показатели скорости приспособления в рамках динамической модели сопоставимы со скоростью приспособления развитых стран.

При анализе структуры капитала компаний 37 стран Гайгорайдиноглу и Озтёкин пришли к выводу, что формирование стратегического соотношения собственного и заемного капитала может быть описано как компромиссной концепцией, так и теорией порядка финансирования (Gungoraydinoglu, Öztekin, 2011).

В исследовании Де Хаaса и Питерса (De Haas, Peeters, 2006) протестировано четыре спецификации динамической модели структуры капитала на данных 10 стран ЦВЕ. Авторы установили, что компаниям из стран с переходной экономикой свойственно движение в направлении целевого уровня долговой нагрузки, однако ввиду неразвитости банковского сектора в данных странах скорость приспособления невелика.

Подводя итоги результатам проверки динамической модели на развивающихся рынках, стоит заметить, что результаты разнятся не только ввиду отличий рынков и компаний, функционирующих на данных рынках, но и виду различных применяемых методов. Как замечают Данг и соавторы (Dang et al., 2012) оценки скорости приспособления, полученные с помощью сквозных регрессий МНК, смещены в сторону уменьшения, в то время как оценки моделей с фиксированными эффектами завышены, а оценки, полученные обобщенным методом моментов, представляют некие средние значения.

\section{Методология исследования структуры капитала компаний с развивающихся финансовых рынков}

В представленном исследовании автором вводится предположение, согласно которому современная динамическая компромиссная теория позволяет при моделировании объединить в себе факторы ряда традиционных и альтернативных теорий структуры капитала. Компании придерживаются оптимального интервала структуры капитала, внутри данного интервала структура капитала определяется мотивами компромисса, агентскими мотивами и поведенческими мотивами. Скорость приспособления при этом определяется рядом макроэкономических и институциональных показателей, а также мотивами порядка финансирования и отслеживания рынка капитала. С целью доказательства данного утверждения, были сформулированы следующие гипотезы.

Гипотеза 1. Компании, оперирующие на рынках стран БРИК, формируют политику финансирования, руководствуясь различными мотивами, что не позволяет рассматривать данные компании в объединенной выборке.

Гипотеза 2. Компании, оперирующие на рынках стран ВE, формируют политику финансирования, руководствуясь сходными мотивами, что позволяет рассматривать данные компании в объединенной выборке.

Гипотеза 3. Целевой уровень долговой нагрузки зависит от традиционных детерминант - специфических характеристик компаний, среди которых: ожидаемый в будущем рост компании, размер ее совокупных активов, доходность капитала и структура активов.

Гипотеза 4. Целевой уровень долговой нагрузки зависит от ряда дополнительных детерминант: величины дивидендных выплат, уровня риска компании, структуры собственности, отраслевой принадлежности и агентских издержек.

Гипотеза 5. Формирование структуры капитала компаний на развивающихся рынках может быть описано динамической компромиссной концепцией. 
Гипотеза 6. Компании, функционирующие на развивающихся рынках капитала, имеют ненулевые издержки приспособления.

Гипотеза 7. Скорость приспособления зависит от таких показателей, как доступность кредитов, экономический рост, инфляция, развитость национального фондового рынка, детерминант концепций отслеживания рынка капитала и порядка финансирования.

Гипотеза 8. Скорость приспособления в условиях долговой нагрузки, не достигающей целевого уровня, тем ниже, чем выше показатель МТВ.

Гипотеза 9. Скорость приспособления в условиях наличия внутреннего финансового дефицита тем выше, чем ниже уровень долговой нагрузки по отношению к целевому показателю.

Гипотеза 10. Кризисный период оказал значимое влияние на принятие фирмами решений о финансировании, увеличив скорость приспособления компаний к целевому уровню долговой нагрузки.

\section{Характеристика выборки и переменных анализа}

Для реализации исследования была сформирована выборка по крупным компаниям стран БРИК и ВЕ, включающая в себя данные за 2002-2010 финансовые годы. Основной массив данных, представляющих собой данные финансовой отчетности компаний, был получен из базы данных Bloomberg. В силу отсутствия интересующих данных по ряду компаний выборка пополнялась за счет отчетностей, взятых с официальных сайтов компаний, а также с сайтов национальных бирж, тем не менее итоговая выборка представляет собой частично несбалансированную модель. Макроэкономические показатели собраны из базы Всемирного Банка. Принимая во внимание специфику формирования структуры капитала компаниями финансового сектора и сферы недвижимости, компании, представляющие данные отрасли, в выборку включены не были.

В целях получения результатов, сопоставимых с существующими исследованиями по структуре капитала, а также для анализа робастности результатов в исследовании было проанализировано девять показателей долговой нагрузки: основанные на процентных долгах (краткосрочном, долгосрочном, совокупном), нормированные на сумму совокупного процентного долга и балансовой стоимости собственного капитала; основанные на обязательствах компании (краткосрочных, долгосрочных, совокупных), нормированных на величину совокупных активов; основанных на процентных долгах (краткосрочных, долгосрочных, совокупных), нормированных на сумму совокупного процентного долга и рыночной стоимости собственного капитала.

В ходе анализа целевой структуры капитала и детерминант скорости приспособления рассматривался ряд независимых переменных, отвечающих за традиционные детерминанты структуры капитала, медианные показатели долговой нагрузки по отрасли и по стране, налоговые факторы, показатели агентских издержек, внутреннего финансового дефицита, теории отслеживания рынка, показатели структуры собственности, макроэкономические параметры развития страны, ряд дамми-переменных, отвечающих за отраслевую принадлежность компании и формат предоставляемой ей финансовой отчетности. Обозначения переменных и способ их расчета представлены в приложении.

\section{Модель движения к целевой структуре капитала}

Анализ формирования структуры капитала на развивающихся рынках проводился в несколько этапов. Основной этап подразумевает построение динамической модели формирования структуры капитала. Согласно анализируемой нами модели, выбор структуры капитала может быть описан следующим образом:

$$
\left(L_{i t}-L_{i t-1}\right)=\beta_{0}+\beta_{1}\left(L_{i t}^{*}-L_{i t-1}\right)+\beta_{2} Z+\varepsilon_{i t},
$$

где: 
$L_{i t}$ - показатель структуры капитала $i$-й компании в момент времени $t$;

$L_{i t}^{*}$ - целевая структура капитала $i$-й компании в момент времени $t$;

$Z$ - вектор переменных, влияющих на скорость приспособления структуры капитала к целевому уровню.

Данная модель (уравнение 1) показывает, что, принимая решение об изменении структуры капитала в данном периоде, менеджмент фирмы анализирует сложившееся в предыдущем периоде отклонение фактической долговой нагрузки от некого целевого уровня. При этом параметр $\beta_{1}$ отвечает за скорость приспособления, отражающую, насколько сокращается разница между фактическим и целевым уровнем долга в течение одного периода. Чем выше $\beta_{1}$, тем быстрее компания стремится достичь целевой структуры капитала.

Первоначально необходимо определить данный целевой уровень долговой нагрузки. Следуя методологии Ванзенрида (Wanzenried, 2006), целевая структура капитала определяется на первом этапе и на втором этапе используется для анализа модели частичного приспособления. Предполагается, что целевая структура $i$-й компании меняется с течением времени и зависит от ряда индивидуальных характеристик компании.

$$
L_{i t}=\gamma_{o}+\gamma_{1} \ln \text { sales }_{i t}+\gamma_{2} \text { prof }_{i t}+\gamma_{3} \tan \text { gibility }_{i t}+\gamma_{4} \text { growth }_{i t}+\gamma_{5} Y_{i t}+v_{i t},
$$

где $y_{i t}$ - вектор детерминант, отличных от традиционных детерминант структуры капитала, влияющих на определение целевого показателя структуры капитала.

На данном этапе в рамках панельного анализа оцениваются три вида регрессий: сквозная (pooled), регрессия с детерминированным эффектом (fixed effect) и регрессия со случайным эффектом (random effect). У сквозной модели нет возможности уловить такие характеристики, различающиеся от компании к компании, как издержки финансовой неустойчивости, либо отраслевые характеристики (Booth et al., 2001). Получаемые таким образом оценки в условиях несбалансированности панели не являются ни эффективными, ни несмещенными. В случае использования модели с фиксированными эффектами влияние упущенных переменных может быть учтено за счет изменяющегося коэффициента при свободном члене. Однако и оценки, полученные посредством построения моделей с фиксированными эффектами, могут быть смещенными. Предпосылки модели со случайными эффектами во многом нереалистичны. В итоге для получения робастных материалов стоит проверить все три модели и протестировать их на наиболее подходящую спецификацию с помощью тестов: F-теста, теста Брейша-Пагана и теста Хаусмана. Полученные коэффициенты при детерминантах итоговых регрессий были использованы для расчета целевой структуры капитала и инкорпорированы в уравнение (1). Использование в исследовании панельных данных позволяет получить более эффективные оценки параметров модели. Однако наличие постоянных во времени ненаблюдаемых индивидуальных эффектов приводит к тому, что оценки параметров динамической модели, полученные с помощью метода наименьших квадратов, оказываются несостоятельными. Причиной несостоятельности является наличие корреляции между лаговой переменной $L_{i t-1}$ и случайной ошибкой $\varepsilon_{i t}$, которая включает в себя ненаблюдаемые индивидуальные эффекты: $\varepsilon_{i t}=\alpha_{i}+u_{i t}$, где $\alpha_{i}-$ ненаблюдаемые индивидуальные эффекты. При этом следует отметить, что наличие корреляции между лаговой переменной и случайной ошибкой не зависит от природы индивидуальных эффектов, то есть от того, являются ли индивидуальные эффекты случайными или детерминированными.

При последующем анализе динамической модели получить состоятельные оценки параметров динамической регрессионной модели позволяет метод Ареллано и Бонда (Arellano, Bond, 1991), суть которого заключается в нахождении оценок с помощью обобщенного метода моментов путем перехода к уравнениям в первых разностях для исключения ненаблюдаемых индивидуальных эффектов. В данной модели лаговая зависимая переменная $\left(\mathrm{L}_{\mathrm{it}-1}\right)$ зависит от индивидуального фиксированного эффекта. Следовательно, при 
стремлении количества групп к бесконечности и фиксированном количестве временных периодов оценка модели методом фиксированных эффектов будет смещенной и несостоятельной. Для решения проблемы используют обобщенный метод моментов (ОММ) Ареллано-Бонда (Miguel, Pindado, 2001; Flannery, Rangan, 2006; Lemmon et al., 2008). Однако при больших значениях авторегрессионного параметра $\beta$ (близких к единице) оценки коэффициентов оказываются смещенными ввиду слабости используемых инструментов (Blundell, Bond, 1998). Для получения более точных оценок применяется модифицированный вариант ОММ Ареллано-Бонда - метод Бланделла-Бонда (Blundell, Bond, 1998; Lemmon et al., 2008; Hovakimian, 2011). В данном исследовании модель оценивалась двумя способами для выявления устойчивых результатов.

Для тестирования гипотез, отвечающих за различия в политике финансирования между странами, страновые фиктивные переменные вводились как на этапе тестирования детерминант целевой долговой нагрузки, так и на этапе тестирования динамической компромиссной модели.

Анализ детерминант скорости приспособления проводился путем раздельного включения детерминант, так как включение нескольких детерминант значительно увеличило бы количество переменных (за счет перемножения детерминант скорости приспособления и целевого финансового рычага) и сократило степени свободы. Кроме того, одновременное включение макроэкономических переменных привело бы к возникновению проблемы корреляции этих переменных.

Заключительный этап анализа динамической модели подразумевает рассмотрение влияния кризисных данных на политику финансирования компаний на развивающихся рынках капитала. Для проведения данного анализа в первую очередь были проверены на значимость дамми-переменные, относящиеся к 2007, 2008 и 2009 годам (при анализе целевой структуры капитала, факторов агентской концепции, скорости приспособления в динамической модели). Ввиду того что, в зависимости от страны, кризис начал оказывать влияние на внутренние решения компаний либо в 2007, либо в 2008 году, была проверена значимость дамми-переменных на каждый из 2007-2009 годов. Было проверено также, остаются ли компании верны политике динамического выбора структуры капитала, определенной до кризиса, в кризисный период посредством разбиения выборки на два временных периода и сравнения получаемых результатов.

\section{Ключевые результаты тестирования структуры капитала}

Дескриптивный анализ уровня долговой нагрузки позволил выявить общие черты для $\mathrm{BE}$ и значимые различия в параметрах заемного финансирования стран БРИК. Анализ выборки до и после кризиса показал идентичные тенденции в изменениях долговой нагрузки в странах БРИК и ВЕ. В 2008 году наблюдалось увеличение всех показателей долговой нагрузки, при этом наиболее значительные изменения относятся к рыночным данным. Начиная с 2009 года показатели долговой нагрузки начали постепенно возвращаться к докризисному уровню, однако к концу 2010 года показатели на основе балансовых стоимостей остаются несколько выше докризисных.

Результаты выявления детерминант целевого уровня долговой нагрузки

На первом этапе эконометрического анализа формирования структуры капитала на развивающихся рынках капитала были протестированы гипотезы, относящиеся к страновым различиям в формировании соотношения собственного и заемного капиталов. Проведенные на примере показателя совокупного уровня долговой нагрузки и традиционных детерминант тесты Чоу позволили заключить, что объединение в одну выборку компаний, принадлежащих к странам БРИК и ВЕ, невозможно. На следующем этапе рассматривалась возможность анализа структуры капитала по данным группам. Было установлено, что группа 
компаний ВЕ может быть рассмотрена вместе, в то время как компании из разных стран БРИК не могут быть проанализированы в рамках совокупной выборки. Результаты проведенного теста Чоу также не позволяют анализировать до- и посткризисные данные вместе с кризисными.

Следующий этап исследования позволил выявить детерминанты целевого уровня долговой нагрузки.

Было выявлено, что более прибыльным компаниям присущ более низкий уровень долговой нагрузки. Данный результат сохраняется не только в абсолютном большинстве спецификаций модели, но и для всех страновых выборок. Отмеченный эффект подтверждается исследованиями, выполненными по компаниям с других развивающихся рынков капитала (Nivorozhkin, 2002; Cornelli et al., 1996; Hussain et al., 1997). Характер зависимости не меняется и во времени: результаты до и после кризиса подтверждают обратную зависимость, при этом после кризиса результаты еще более устойчивы.

Во-вторых, установлено разноплановое влияние, оказываемое структурой активов на уровень долговой нагрузки. До кризиса структура активов практически не оказывала влияния на формирование структуры капитала, в тех же спецификациях, где данное влияние было установлено, наблюдалась ожидаемая прямая зависимость. После кризиса влияние структуры актива стало более очевидным, при этом для компаний Индии наблюдается прямая зависимость, для компаний ВE и России - обратная, а для Бразилии и Китая результаты зависят как по годам, так и по переменным долговой нагрузки. Одной из возможных причин нестандартной формы зависимости может быть низкая залоговая стоимость долгосрочных материальных активов в компаниях на развивающихся рынках капитала.

B-третьих, неодинаковое влияние на структуру капитала компаний на развивающихся рынках оказывает и размер капитала компании. Для выборок компаний Китая, ВЕ была выявлена ожидаемая прямая зависимость уровня долговой нагрузки от размера капитала компании, выраженного логарифмом продаж. Для выборки компаний Бразилии и России структура капитала оказалась в обратной зависимости от размера капитала компании при всех способах расчета независимой переменной. Неоднозначные результаты показывают модели, рассчитанные на данных Индии.

В-четвертых, возможности роста также оказывают значимое влияние на выбор компаниями структуры капитала. При этом прямая зависимость наблюдается для индийских компаний и российских компаний после кризиса, обратная зависимость - для компаний Китая и ВЕ. Для компаний Бразилии до кризиса прямая зависимость наблюдалась для краткосрочных показателей долговой нагрузки, а обратная - для долгосрочных. Для российских компаний до кризиса ожидаемая обратная зависимость была характерна для показателей долговой нагрузки, основанных на рыночной стоимости собственного капитала, в то время как для показателей, основанных на обязательствах компаний, зависимость была прямой.

В-пятых, среди иных детерминант, оказывающих влияние на уровень долговой нагрузки, значимы переменные уровня риска компании; показатели агентской концепции (свободный денежный поток в распоряжении менеджмента, степень уникальности активов, коэффициент использования активов); показатели структуры собственности (доля акций мажоритарного акционера), владение акциями иностранными инвесторами, государством, менеджментом; степень независимости совета директоров; а также отраслевые дамми и дамми-переменная, отвечающая за составление отчетности в соответствии с форматом МСФО.

Таким образом, проведенный анализ компаний наиболее крупных стран из группы БРИК свидетельствует о специфичности воздействия исследованного набора детерминант на структуру капитала оцениваемых выборок компаний в каждой стране. Это означает, что разрабатывая политику финансирования, менеджмент крупных компаний России, Бразилии, Индии и Китая, а также компаний ВЕ опирается на разные наборы факторов, а значит, 
свойственные той или иной стране средние показатели структуры капитала крупных компаний формируются под влиянием разных аргументов.

\section{Результаты тестирования динамической компромиссной концепции}

Результаты тестирования динамической компромиссной концепции показывают, что компаниям группы стран БРИК и ВЕ свойственно движение к целевому уровню, определенному на предыдущем шаге исследования, при этом ввиду наличия издержек приспособления целевая структура капитала не достигается компаниями за один период.

В рамках данного исследования для каждой страны группы стран БРИК и для стран ВЕ были построены динамические модели для каждого из девяти показателей долговой нагрузки, а также следующие модификации модели: включение показателя доступности заемного финансирования, темпов роста ВВП на душу населения, уровня инфляции, степени развитости фондового рынка, показателя внутреннего финансового дефицита компании, показателя отслеживания рынка МТВ, показателя средневзвешенного по внешнему финансированию МТВ, модель на основе предкризисных данных и на посткризисных данных. Полученные результаты представлены в таблице 1.

Таблица 1

Скорость приспособления к целевой структуре капитала компаний стран БРИК и ВЕ

\begin{tabular}{|c|c|c|c|c|c|c|c|c|c|c|}
\hline & \multicolumn{2}{|c|}{ Бразилия } & \multicolumn{2}{|c|}{ Россия } & \multicolumn{2}{|c|}{ Индия } & \multicolumn{2}{|c|}{ Китай } & \multicolumn{2}{|c|}{ BE } \\
\hline & TDR & TDRA & TDR & TDRA & TDR & TDRA & TDR & TDRA & TDR & TDRA \\
\hline Совокупная выборка & $0,447 * * *$ & $0,560 * * *$ & 0,221 & $0,321 * * *$ & $0,621 * * *$ & 0,0884 & $0,354 * *$ & $0,431 * * *$ & $0,296 * * *$ & $0,416^{* * *}$ \\
\hline Ставка кредитования & $0,245^{* *}$ & $0,264 * *$ & 0,225 & $0,329 * * *$ & $0,594 * * *$ & $-0,00997$ & $0,363^{* *}$ & $0,374 * * *$ & 0,144 & $0,557 * * *$ \\
\hline Темп роста ВВП & $0,458 * * *$ & $0,579 * * *$ & 0,219 & $0,316^{* * *}$ & $0,624 * * *$ & 0,100 & $0,377^{* *}$ & $0,352 * * *$ & $0,397 * * *$ & $0,449 * * *$ \\
\hline Инфляция & $0,272 * *$ & $0,311^{* *}$ & $0,279 *$ & $0,350 * * *$ & $0,603 * * *$ & 0,0958 & $0,359 * *$ & $0,436 * * *$ & $0,341 * * *$ & $0,359 * * *$ \\
\hline $\begin{array}{l}\text { Развитие фондового } \\
\text { рынка }\end{array}$ & $0,336^{* * *}$ & $0,306^{* *}$ & $0,318 * *$ & $0,369 * * *$ & $0,575^{* * *}$ & 0,114 & $0,346^{* *}$ & $0,412 * * *$ & $0,297 * * *$ & $0,357 * * *$ \\
\hline DEF & $0,452 * * *$ & $0,555^{* * *}$ & $0,385 * * *$ & $0,260 * *$ & $0,636^{* * *}$ & 0,0787 & $0,270 * *$ & $0,381 * * *$ & $0,395 * * *$ & $0,304 * * *$ \\
\hline $\begin{array}{l}\text { DEF при недостаточном } \\
\text { уровне долга }\end{array}$ & $0,322^{* *}$ & $0,394 * *$ & $0,506^{* * *}$ & $0,467 * * *$ & $0,791 * * *$ & $0,226^{*}$ & $0,252 * *$ & $0,431 * * *$ & $0,386 * * *$ & $0,499 * * *$ \\
\hline МТВ & $0,342 * * *$ & $0,501 * * *$ & $-0,0219$ & $-0,0254$ & $0,621 * * *$ & 0,0855 & 0,236 & $-0,310 * *$ & $0,272 * * *$ & $0,364 * * *$ \\
\hline $\begin{array}{l}\text { МТВ при } \\
\text { недостаточном уровне } \\
\text { долга } \\
\end{array}$ & $0,369^{* *}$ & $0,593 * * *$ & $0,269 * *$ & $-0,0189$ & $0,714 * * *$ & $0,257^{* *}$ & $0,248^{*}$ & 0,0892 & $0,327^{*}$ & $0,508 * * *$ \\
\hline EFWAMTB & $0,449 * * *$ & $0,544 * * *$ & $-0,00573$ & $-0,00133$ & $0,625^{* * *}$ & 0,0843 & 0,187 & $-0,436^{* * *}$ & $0,274 * * *$ & $0,362 * * *$ \\
\hline $\begin{array}{l}\text { ЕFWАМТВ при } \\
\text { недостаточном уровне } \\
\text { долга } \\
\end{array}$ & $0,519^{* * *}$ & $0,635 * * *$ & 0,166 & $-0,0606$ & $0,694 * * *$ & $0,255^{* *}$ & $0,212^{*}$ & 0,0834 & $0,318^{*}$ & $0,518 * * *$ \\
\hline До кризиса & $0,427^{* *}$ & $0,697 * * *$ & 0,0912 & $0,428 * *$ & $0,674 * * *$ & $-0,109$ & 0,199 & $0,379 * *$ & 0,110 & $0,586^{* * *}$ \\
\hline После кризиса & 0,102 & 0,0569 & 0,0183 & 0,0373 & 0,232 & $-0,0633$ & $0,546^{* *}$ & 0,269 & $0,362 * * *$ & 0,170 \\
\hline
\end{tabular}

Примечание: TDR - отношение долгосрочного и краткосрочного процентных долгов компании к сумме ее совокупного долга и балансовой стоимости ее акционерного капитала; TDRA - отношение совокупных обязательств компании к балансовой стоимости ее активов; каждая цифра в таблице отражает коэффициент перед отклонением фактического уровня долговой нагрузки от целевого значения, т.е. $\left(1-\beta_{1}\right)$.

На основе полученных результатов можно сделать следующие ключевые выводы.

Bo-первых, компании, функционирующие на развивающихся рынках капитала, определяют в качестве целевых уровней долговой нагрузки показатели TDR и TDRA, т.е. рассматривают отношение совокупного долга либо к сумме совокупного долга и бухгалтерской стоимости собственного капитала, либо к величине совокупных активов. Таким образом, именно совокупный долг в развивающихся странах расценивается 
менеджментом компании как источник ее стратегического развития.

Во-вторых, компаниям на развивающихся рынках не свойственно устанавливать в качестве цели показатели долговой нагрузки, основанные на рыночных показателях (значимые результаты получены только для Бразилии и для краткосрочных показателей Индии и Китая), что связано с невозможностью контроля данных показателей со стороны менеджмента в условиях слабой развитости финансовых рынков.

B-третьих, средние уровни скорости приспособления по совокупным национальным выборкам намного выше показателей компаний с развитых рынков и составляют от 38 до $71 \%$ за период. Однако стоит заметить, что на данные показатели оказывает влияние кризисный период. Соответственно, рассмотрение подвыборок за периоды 2002-2007 и 2008-2010 годов позволило установить, что в среднем скорость приспособления до кризиса была ниже и составляла порядка 31-58\%. Данный факт связан со слишком резкими изменениями уровня долговой нагрузки в период кризиса и после него, что нередко приводило к более чем 100\%-ной корректировке долговой нагрузки за период.

В-четвертых, макроэкономические показатели оказывают влияние на скорость приспособления. Скорость приспособления прямо связана со ставкой кредитования в стране, темпом роста ВВП, ставкой инфляции, уровнем развития фондового рынка.

B-пятых, мотивы отслеживания рынка капитала и порядка финансирования оказывают значимое влияние на скорость приспособления. При этом эффект, оказываемый данными мотивами на скорость приспособления, различен в зависимости от превышения фактическим уровнем долговой нагрузки целевого уровня или наоборот. Так, для выборок Китая и Бразилии скорость приспособления в условиях внутреннего финансового дефицита увеличивается, что соответствует поставленной гипотезе. На данных других подвыборок наличие финансового дефицита приводит к снижению скорости приспособления в любом случае и может рассматриваться как альтернативный мотив, в соответствии с которым компании выбирают структуру капитала, а следовательно, данным компаниям свойственно в меньшей степени придерживаться целевого уровня.

Включение в модель переменных, отвечающих за мотив отслеживания рынка капитала, показывает противоречивые результаты, однако при ограничении на недостижение целевого уровня демонстрирует ожидаемую обратную зависимость: при более высоких показателях МТВ и средневзвешенного по внешнему капиталу МТВ скорость приспособления снижается, так как компании в меньшей степени заинтересованы в увеличении долговой нагрузки и в большей степени - в привлечение собственного капитала.

\section{Заключение}

Проведенное исследование выбора структуры капитала компаниями с развивающихся финансовых рынков позволило сделать вывод о значимости динамической компромиссной концепции в выборе соотношения собственного и заемного капиталов. При этом было установлено, что традиционные детерминанты структуры капитала, выявленные на данных компаний развитых рынков капитала, также оказывают влияние на целевой уровень долговой нагрузки компаний БРИК и ВЕ. Однако на целевой финансовый рычаг также воздействуют факторы, отражающие агентские мотивы, структуру собственности и корпоративного управления, отраслевую принадлежность компании. Скорость приспособления к целевому показателю долга зависит от макроэкономических показателей (темп инфляции, темп роста ВВП, уровень развития рынка капитала), так и от детерминант концепций порядка финансирования и отслеживания рынка капитала.

Структура капитала компаний развивающихся рынков капитала требует дальнейшего анализа. Необходимо более подробное исследование целевого уровня долговой нагрузки и тестирование гипотезы о наличии оптимального диапазона структуры капитала, а не единичного значения соотношения собственного и заемного капиталов. Вопросы экзогенности структуры капитала и структуры собственности, инвестиционных решений и 
решений о политике выплат также нуждаются в тщательном исследовании.

\section{Список литературы}

1. Arellano, M., and Bond, S. (1991), Some Tests of Specification for Panel Data: Monte Carlo Evidence and an Application to Employment Equations, The Review of Economic Studies, 58 (1991) 277-297.

2. Bessler, W., Drobetz, W., and Grüninger, M.C. (2011), I nformation Asymmetry and Financing Decisions. International Review of Finance, 11(1) (2011) 123-154.

3. Blundell, R.W., and Bond, S.R. (1998), Initial Conditions and Moment Restrictions in Dynamic Panel Data Models, Journal of Econometrics, 87 (1998) 115-143.

4. Booth, L., Varouj, A., Demirguk-Kunt, A., Maksimovic, V. (2001), Capital Structures in Developing Countries, Journal of Finance, 56 (2001) 87-130.

5. Clark, B., Francis, B., Hasan, I. (2009), Do firms adjust toward target capital structures? Some international evidence. Available at SSRN: http://ssrn.com/abstract $=1364095$ or http://dx.doi.org/10.2139/ssrn.1364095.

6. Cornelli, F. , Portes, R., and Schaffer, M.E. (1996), The Capital Structure of Firms in Central and Eastern Europe, CEPR Discussion Paper No. 1392.

7. Dang, V.A. (2003), Testing capital structure theories using error correction models: evidence from the UK, France and Germany, Applied Economics, 45(2) (2013) 171-190.

8. De Haas, R., and Peeters, M. (2006), The Dynamic Adjustment Towards Target Capital Structures of Firms in Transition Economies, Economics of Transition, 14 (2006) 133-169.

9. Flannery, M. J., and Rangan, K.P. (2006), Partial Adjustment toward Target Capital, Journal of Financial Economics, 41 (2006) 41-73.

10. Gungoraydinoglu, A., Özterkin, Ö. (2001),Firm- and country-level determinants of corporate leverage: Some new international evidence. Journal of Corporate Finance, 17 (2011) 1457-1474.

11. Hovakimian, A., and Li, G. (2011), In Search of Conclusive Evidence: How to Test for Adjustment to Target Capital Structure, Journal of Corporate Finance, 17 (2011) 33-44.

12. Hussain, Q., Nivorozhkin, E. (1997), The Capital Structure of Listed Companies in Poland. IMF Working Paper. P. 1-27. Available at SSRN: http://ssrn.com/abstract=883923.

13. Lemmon, M.L., Roberts, M.R., Zender, J.F. (2008), Back to the Beginning: Persistence and the Cross-Section of Corporate Capital structure, The Journal of Finance, 4(LXIII) (2008) $1575-1608$.

14. Mendes, E., Kayo, E., Cruz, L.B. (2005), Capital Structure and Windows of Opportunities: Tests in the Brazilian Market,2 (2005). Available at SSRN: http://ssrn.com/abstract $=677561$ or http://dx.doi.org/10.2139/ssrn.677561.

15. Miguel, A., Pindado, J. (2001), Determinants of the capital structure: New evidence from Spanish data, Journal of Corporate Finance, 7 (2001) 77-99.

16. Mitton, T. (2008), Why Have Debt Ratios Increased for Firms in Emerging Markets? European Financial Management, 14(1) (2008) 127-151.

17. Ni, Y., Guo, S., Giles, D.E. (2010),Capital structures in an emerging market: a duration analysis of the time interval between IPO and SEO in China, Applied Financial Economics, 20 (2010) 1531-1545.

18. Nivorozhkin, E. (2002), Capital Structures in Emerging Stock Markets: The case of Hungary. The Developing Economies, 2(XL) (2002) 166-187.

19. Nivorozhkin, E. (2005), Financing choices of firms in EU accession countries. Emerging Markets Review, 6 (2005) 138-169.

20. Özterkin, Ö., Flannery, M.J. (2012), Institutional Determinants of Capital Structure Adjustment Speeds, Journal of Financial Economics, 103 (2012) 88-112.

21. Pandey, I.M. (2001), Capital Structure and the firm characteristics: Evidence from an emerging market. IIMA Working Paper, 10 April. Available at SSRN: 
http://ssrn.com/abstract=300221 or http://dx.doi.org/10.2139/ssrn.300221.

22. Seifert, B., Gonenc, H. (2010), Pecking Order Behaviour in Emerging Markets, Journal of International Financial Management and Accounting, 2(21) (2010) 1-31.

23. Seppa, R. (2008), Capital structure decisions: research in Estonian non-financial companies, Baltic Journal of Management, 3(1) (2008) 55-70.

24. Tong, G., Green, C.J. (2005), Pecking order or trade-off hypothesis? Evidence on the capital structure of Chinese companies, Applied Economics, 37(19) (2005) 2179-2189.

25. Umutlu, G. (2008), Pecking Order and Timing Effects on Aftermarket Performance of IPOs: Evidence from Turkey. International Research Journal of Finance and Economics, 18 (2008) $142-150$.

26. Wanzenried, G. (2006), Capital Structure Dynamics in the UK and Continental Europe. The European Journal of Finance. 8(12) (2006) 693-716. 
Приложение. Независимые переменные, используемые для анализа структуры капитала на развивающихся рынках капитала

\begin{tabular}{|c|c|}
\hline Переменная & Описание переменной \\
\hline Tangibility & $\begin{array}{l}\text { Структура активов, выраженная долей внеоборотных активов } \\
\text { в совокупных активах компании }\end{array}$ \\
\hline Prof & $\begin{array}{l}\text { Доходность совокупного капитала, выраженная отношением } \\
\text { прибыли до выплаты процентов и налогов к совокупным } \\
\text { активам компании }\end{array}$ \\
\hline Lnsales (Lnassets) & $\begin{array}{l}\text { Размер капитала } \text { компании, выраженный натуральным } \\
\text { логарифмом продаж (совокупных активов) компании }\end{array}$ \\
\hline Growth & $\begin{array}{l}\text { Возможности роста компании, выраженные отношением } \\
\text { капиталовложений к совокупным активам компании }\end{array}$ \\
\hline NDT & $\begin{array}{l}\text { Недолговой налоговый щит, выраженный отношением } \\
\text { амортизации к совокупным активам }\end{array}$ \\
\hline Tax & $\begin{array}{l}\text { Долговой налоговый щит, выраженный } \text { отношением } \\
\text { величины выплаченного налога на прибыль к показателю } \\
\text { прибыли до налогов }\end{array}$ \\
\hline Div & $\begin{array}{l}\text { Величина дивидендных выплат, выраженная } \\
\text { выплаченных дивидендов в чистой прибыли }\end{array}$ \\
\hline $\begin{array}{l}\text { MTB (market-to- } \\
\text { book ratio) }\end{array}$ & $\begin{array}{l}\text { Отношение рыночной стоимости акционерного капитала к } \\
\text { балансовой стоимости акционерного капитала }\end{array}$ \\
\hline EFWAMTB & $\begin{array}{l}\text { Средневзвешенное по внешнему финансированию } \\
\text { отношение рыночной стоимости акционерного капитала к } \\
\text { балансовой стоимости акционерного капитала }\end{array}$ \\
\hline Risk & $\begin{array}{l}\text { Уровень делового риска, выраженный волатильностью } \\
\text { доходности, рассчитываемой как среднеквадратичное } \\
\text { отклонение показателя операционной прибыли к совокупным } \\
\text { активам компании }\end{array}$ \\
\hline FCFag & $\begin{array}{l}\text { Свободный денежный поток в управлении менеджментом, } \\
\text { рассчитываемый как операционная прибыль до уплаты } \\
\text { процентов, налогов и амортизации за вычетом налогов, } \\
\text { процентов и выплаченных дивидендов, нормированная на } \\
\text { величину совокупных активов }\end{array}$ \\
\hline $\begin{array}{l}\text { VoA (vola } \\
\text { asset utiliz }\end{array}$ & Волатильность показателя использования активов \\
\hline AssetUni & $\begin{array}{l}\text { Степень уникальности активов, рассчитываемая как доля } \\
\text { общих, коммерческих и административных расходов в } \\
\text { выручке. }\end{array}$ \\
\hline AssetUti & Коэффициент использования активов \\
\hline $\mathrm{DEF}$ & $\begin{array}{l}\text { Внутренний дефицит финансирования компании, } \\
\text { рассчитываемый как сумма дивидендных выплат и } \\
\text { инвестиционного денежного потока за отчетный период за } \\
\text { вычетом денежного потока, полученного от операционной } \\
\text { деятельности, нормированная на совокупные активы } \\
\text { компании }\end{array}$ \\
\hline BoD indep & $\begin{array}{l}\text { Степень независимости совета директоров, рассчитываемая } \\
\text { как доля независимых членов совета директоров }\end{array}$ \\
\hline State & $\begin{array}{l}\text { Фиктивная переменная, отвечающая за структуру } \\
\text { собственности компании и равная единице в случае наличия }\end{array}$ \\
\hline
\end{tabular}




\begin{tabular}{|c|c|}
\hline Пере & Описание переменной \\
\hline & контрольного пакета акций у государства \\
\hline Foreign & $\begin{array}{l}\text { Фиктивная переменная, отвечающая за структуру } \\
\text { собственности компании и равная единице в случае наличия } \\
\text { контрольного пакета акций у иностранного инвестора }\end{array}$ \\
\hline Management & $\begin{array}{l}\text { Фиктивная переменная, отвечающая за структуру } \\
\text { собственности компании и равная единице в случае наличия } \\
\text { контрольного пакета акций у менеджмента компании }\end{array}$ \\
\hline Maj_1 & $\begin{array}{llccc}\text { Доля акций, } \\
\text { мажоритарногодящаяся акционера }\end{array}$ \\
\hline Country & $\begin{array}{l}\text { Набор фиктивных переменных, отражающих } \\
\text { принадлежность компании к той или иной стране. } \\
\text { Для анализа особенностей стран БРИК и ВE, сформирована } \\
\text { переменная: Country_BRIC }\end{array}$ \\
\hline Crisis & $\begin{array}{l}\text { Фиктивная переменная, отвечающая за принадлежность } \\
\text { данных к кризисному периоду. Сформированы две } \\
\text { переменные: Crisis1 (2007-2008 годы), Crisis2 (2008-2009 } \\
\text { годы) }\end{array}$ \\
\hline Industry & $\begin{array}{l}\text { Набор фиктивных переменных, отражающих } \\
\text { принадлежность компании к той или иной отрасли. } \\
\text { В данном исследовании сформированы две переменные, } \\
\text { отражающие принадлежность к нефтегазовой отрасли и } \\
\text { отрасли потребительских товаров и ретейла: DOil, DCR }\end{array}$ \\
\hline Acc_St & $\begin{array}{l}\text { Фиктивные переменные, отвечающие за стандарт отчетности, } \\
\text { в соответствии с которым подготовлена финансовая } \\
\text { отчетности компании. }\end{array}$ \\
\hline GDP_Growth & $\begin{array}{l}\text { Показатель экономического роста, выраженный темпом } \\
\text { роста ВВП на душу населения }\end{array}$ \\
\hline Infl (inflation) & Показатель национальной инфляции \\
\hline $\begin{array}{l}\text { CpGDP } \\
\text { (capitalization per } \\
\text { GDP) }\end{array}$ & $\begin{array}{l}\text { Показатель развитости фондового рынка, рассчитываемый } \\
\text { как отношение совокупной капитализации компаний к ВВП }\end{array}$ \\
\hline Lending & $\begin{array}{l}\text { Ставка заимствования как показатель уровня процентных } \\
\text { ставок и доступности кредитов }\end{array}$ \\
\hline
\end{tabular}

